\title{
Accountability in Local Government: Leadership and Organizational Culture when SPI becomes The Moderating Variable
}

\author{
Kadar Nurjaman ${ }^{1}$, Deni Hermana ${ }^{2}$ \\ 1. Doctoral Program in Economics and Management Science, Faculty of Economics and Business, \\ Padjadjaran University, Bandung, Indonesia $₫$ kdr.nurjaman@gmail.com. \\ ${ }^{2}$ Doctoral Program in Economic and Management Science, Faculty of Economics and Business, \\ Padjadjaran University, Bandung, Indonesia \hermana.deni@yahoo.com
}

\begin{abstract}
The objective of this study is to examine the influence of leadership and organizational culture on accountability in local government organization (organisasi perangkat daerahOPD) in West Java with internal control system (sistem pengendalian internal-SPI) as moderating variable. This research is a descriptive and verification survey explanatory study on 240 local government organizations in West Java. The unit of observation was 720 employees in local government organizations. The data analysis was conducted by using SEM Amos. The findings of this study show that SPI is inseparable from local government governance systems. The influence of leadership on accountability is significant with the magnitude of influence on the strong level. In contrast, organizational culture has an effect on accountability at a low level. Both variables significantly affect accountability. SPI strengthens leadership and culture towards accountability. SPI is embedded in the OPD governance system and is integrated into OPD organizational structures. Thus, leadership and organizational culture are significant predictors for accountability in OPD which is strengthen by SPI. The findings have managerial implications particularly in regards to the integration of SPI into governance system of OPD to strengthen leadership and culture.
\end{abstract}

Keywords: internal control system (SPI), leadership, organizational culture, and local government

\section{Introduction}

Realizing credible local government institutions has become a difficult effort, especially for government agencies that have limited access to sources of knowledge. OPD (local government organization) requires a foundation of concepts that can serve as a basis for solving accountability problems. Veljković et al. (2014) proposes the concept of benchmarking in realizing a governance sysytem which is more open and transparent, while encouraging participation and collaboration. The framework for building accountability is based on the financial paradigm. According to Gadene (2017), accountability is achieved through sound financial / tax management. Ferry \& Murphy (2017) argue that accountability is linked to finance and transparency, focusing on financial accountability. Performance of Government Agencies set forth in Instructions of the President of the Republic of Indonesia Number 7 of 1999, Government Institution Performance Accountability System consisting of stages of Strategic Planning, Performance Planning, Performance Determination, Performance Measurement and Performance Reporting is a manifestation of efforts to provide justice for society as the main virtue of public institutions. The fact according to LAKIP Ministry of Empowerment of State Apparatus and Bureaucracy Reform (2016), performance indicators that are not successful is related to the target districts / cities that have good bureaucracy reform and good accountability and districts/cities that have held a good system of integrity. In West Java, the assessment results show only some successful districts/cities with AA value for the good implementation of the system integration.

Pearson and Suterland (2017) argue that the phenomenon of accountability is growing, complex and elusive. Frey et al. (2013) states that one of the weaknesses in building accountability is the lack of 
adequate theoretical basis of public management systems. A multidisciplinary approach to public accountability can serve as a framework for solving public accountability problems, especially in developing countries with many limitations in the delivery of public services.

Leadership as a predictor of public accountability. Jenkin (2014) argues that accountability and leadership emerge repeatedly as a central theme in organizational governance. Crowe (2011) points out leadership and accountability in public institutions. Babajanien (2008) argues that in the era of regional autonomy, leaders have responsibility to realize accountability. Cowton (2001) and McCall (2001) previously proposed the concept of leadership in relation to accountability. Said and Alam (2015) argue for the importance of accountability in the public sector and strong leadership to control efficiency without abandoning good governance. On the other hand, internal conditions in the form of structures within the organization also determine how these two variables affect accountability as proposed by the Design in the structure of organization affect the accountability (Andre, 2010). The research hypothesis is:

\section{Ha1 Leadership has positive effect on accountability}

Orientation of outcomes by maintaining growth and stability as well as risk taking factor leads the institution to its achievements including accountability. Gelfand et al (2004) examines culture and accountability. Velayutham \& Perera (2004) argue that culture of shame and guilt affects accountability. Velayutham \& Perera (2008) point out the position of culture as a predictor of accountability. Morest (2009) affirms how culture enhances accountability. Middaugh (2007), Morest (2009) put forward an evidence-based culture for accountability. Dubnick (2012) suggests culture as the key to build accountability. Andre (2010) suggests that culture affects accountability. Earlier, Stewart and Kent (2006) argue that there is a strong relationship between internal audit and the level of commitment to risk management. One dimension in organizational culture is the courage to take risks. The research hypothesis is:

\section{$\mathrm{H}_{\mathrm{a} 2}$ Organizational culture has positive effect on accountability}

As a system attached to the organization, the existence of internal control systems (SPI) affect the individual within the organization. Internal control also determines the effectiveness of leadership as well as values and norms. Aziz et al., (2013) explain that internal control systems have an impact on improving the accountability of public institutions. Sanusi et al., (2015) propose an internal control system as a predictor of accountability. Trust and control are important aspects in realizing accountability. The success of realizing public accountability in local government organizations cannot be separated from the existing systems within the organization. Basically, accountability in public institutions has become a commitment in governance. This means that as a system, SPI is integrated into local government governance. Not only in financial reporting systems, accountability covers all dimensions of local governance. The Regulation of the President of the Republic of Indonesia Number 29 of 2014 on the Government Accountability Performance System of Government Institutions in the general provisions state that the Government Institution Accountability System, hereinafter referred to as SAKIP, is a systematic chain of activities, tools and procedures designed for the purpose of assigning and measuring, data collection, classification, , and performance reporting on government agencies, in the context of accountability and performance improvement of government agencies. The regulation is forcing and binding on the implementation of local government.

Therefore, SPI is a must or obligation that must be fulfilled considering 1) policy as a decision indicates that the policy binds individuals and institutions within the scope of the policy; 2) policy as the values and norms that have the authority to support the government's actions within its jurisdiction. SPI assists in the efforts to realize accountable governance; 3) the policy as the management process shows that the policy of organizing efforts to achieve the objectives or solving the problems in internal control;4) the policy also has the function of organizing and binding the whole society on the basis of values. The government has enormous powers to intervene through the 
policy; 5) such provision as Democratic Governance is defined as the interaction of the state with its people in its ranges in order to overcome public problems.

Merchant and Otley (2007) argue that the management control system is designed to help organizations adapt to environment and deliver key results desired by stakeholder groups. The government is concerned that the OPD can realize accountability. The internal control system is not only related to accounting and reporting. The system deals with leadership and organizational communication functions and processes, internally and externally, and includes procedures in the performance of results-oriented work in the form of public accountability. Internal controls encourage organizations to operate in an orderly, efficient, and effective system and achieve planned results. Internal controls provide value to improve the consistent effort of realizing accountability.

There is a relationship between internal control system, leadership, culture and accountability. Hernandez (2016) proposes internal control system as a moderation of organizational culture. Institutions need to establish internal control standards as control which is necessary to ensure quality in the process, to identify existing values and beliefs and to work to generate accountability. Von and Pfister (2009) suggest how the cultural function of the internal control system. Internal control system applied to several OPDs will strengthen the leadership function and established values oriented towards the realization of accountability. The research hypotheses are:

$\mathrm{H}_{\mathrm{a} 3} \mathrm{SPI}$ as a moderating variable that strengthens the influence of leadership on accountability

$\mathrm{H}_{\mathrm{a} 4}$ SPI as a moderating variable that strengthens the influence of organization culture on accountability

\section{Methods}

This study is a descriptive verification survey research on 240 OPD with employee observation unit consisting of auditor and staff. The internal control system is measured by the control environment, risk assessment, control activities, information and communication, and monitoring.

Leadership is measured by the dimensions of direction setter, spokeperson, change agent, and coach. Organizational culture is measured by innovation and risk taking, attention to details, outcome orientation, people orientation, team orientation, aggressiveness, and steadiness. Accountability is measured by legal accountability and honesty, process accountability, program accountability, and policy accountability. The data analysis technique of this study is structural equal modeling.

\section{Results and Discussion}

Performance Accountability of OPD is a manifestation of the obligations of a government agency to account its responsibility as a public institution. The success/failure of implementation of Programs and Activities that have been mandated by stakeholders in order to achieve organizational mission measurably with the target/performance targets that have been determined through periodic performance reports of government agencies. SPI is integrated into the system of governance and is obligatory including the category. Internal control system consists of 1) control environment; 2) risk assessment; 3) control activities; 4) information and communication; and 5) monitoring of internal controls. SPI has become one of the focus of attention of District/City Government in West Java. Distribution of internal control systems in several cities that do not have much different characteristics tend to be the same. The conditions of districts are quite diverse especially for newly formed districts or those considered as a lagging area compared to others.

The reliability of financial reporting, safeguarding of state assets, and compliance with laws and regulations are indicators of the integration of SPI into the governance system. Local governments are required to optimize the process of audit, review, evaluation, monitoring, and other monitoring activities on the implementation of tasks and functions primarily related to the budget, either local government budget or central government budget. In fact, the SPI has not been attached to the governance of local government organizations as it supposed to be according to the regulations. This 
makes SPI an independent variable that affects accountability. SPI should be attached to accountable governance systems. District governments and municipal governments with a good internal control system are indicated by 1 ) Real attempts to uphold the integrity and ethical values; 2 ) commitment to competence; 3) conducive leadership; 4) the establishment of an organizational structure that suits the needs; 5) appropriate delegation of authorities and responsibilities; 6) the preparation and implementation of sound policies on human resource development within the scope of the OPD.

Internal control system in public institutions is still a problem. This is the same as stated by Aziz et al., (2015). The internal control of public institutions is below the overall internal control in terms of the score. The public sector should focus more on internal control and the appropriate assessment system to become a reliable and efficient sector. The existing conditions seem to be in line with Aziz et al., (2015) where there are still many steps that must be taken to improve the public perception, especially to achieve internal control in the public sector. Observation results of some OPD in the south of West Java find that they have low support in terms of both human resources and information technology infrastructure and control system has not fully function optimally. The control environment is 68 percent on average from the ideal score. Risk assessment is lowest score with 64 percent. The control activities are 66 percent of the ideal score. Information and communication is 67 percent and the highest score is monitoring with 69 percent. The description hypothesis shows that the average system, internal controls are in the category of less good. Internal control system as a system means input, process, and output and outcome is an integrated entity, influenced by various factors, especially internal and external environment. Frey et al., (2013) stress the importance of the process on supervision as part of control. The success of building the internal control system affects the income and government expenditure as stated by Abba and Kakanda (2017). In addition, the success of the internal control system in a organization will increase the accountability of the institution.

OPD leadership in West Java varies from leaders who can effectively direct and influence the system within the organization until the leader is deemed less able to direct the organization in accordance with the OPD strategic plan. The results showed that the OPD leaders were less able to determine the direction of the organization. This is in contrast to what Robbins and Judge (2013) have suggested that leaders must have the ability to influence the group toward achieving goals. Resicks et al., (2006) describe indicators of leadership, namely ethical character and integrity, ethical awareness, people-oriented, motivating, encouraging, empowering, and managing ethical accountability. This means that leaders who are less able to determine the direction of organization is a leader who is less able to build accountability according to concept of leadership by Resicks et al., (2006). Leadership function becomes the key of success to coordinate, communicate, and direct the behavior of organization and subsystem design that support the implementation, especially process of improvement in implementation of program oriented to public interest in a sustainable manner. Overall, the leaders do not encourage members to always improve the ability to achieve the vision. Vision evolves with changes in the environment and in the organization. Vision becomes a reflection of how organizations respond to changes that ultimately lead to changes in the organization as an effort to adapt to change. All the dimensions studied (direction determinants, orators, change agents and as coach for the unexperienced employee) indicate the average of good category. Based on the table, it is known that the lowest score is the direction of 58 percent of the total score or at the less level. the highest is a reliable orator and change agent of 66 percent of the total score. The score of the function of leaders as coaches is 65 percent of the ideal score. A leader of a public institution is required to build credibility, i.e. integrity, sincerity, ability and results that are oriented to the public interest.

OPD with effective leadership is indicated by its ability to influence functional and structural personnel to implement organizational strategy by relying on the strength of organizational personnel, building good work with external organizations and reflecting thoroughly the vision of the organization. It is different from OPD with less effective leadership level. The leadership practices are less able to anticipate changes in the environment, especially demands for more responsive public 
services that can prioritize changes to be made. A less effective leader is less able to find a way out in an urgent situation.

Basically, leadership in public institutions is required to encourage radical change for the division of service work oriented towards the welfare of society, development of the role and responsibility in implementing public services based on the ethics of public services. Moreover, a leader is required to inspire radical structural and cultural change while encouraging the adjustment of thought and behavior. A leader empowers organizational members to make changes. The required leader is the leader who has the courage to shift the fundamental paradigm, even to start a kind of revolution in the mindset and behavior, which changes the organizational / OPD view of the public service. Organizational culture evolves with both internal and external changes. Currently the trend of change in OPD becomes more results-oriented in the form of satisfactory public services. OPD members can feel the exposed belief and value, and basic underlying assumption that have a shared meaning when identifying problems and formulating problem solving. The officers have a common understanding about the meaning of the problem, the problem-solving procedure and the goal of solving the problem. The OPD organizational culture is quite diverse. Creating cultural artifacts, beliefs and values and disseminating basic assumptions to solve problems in accountability can be perceived by OPD members. Dimension of innovation and risk-taking have a relation to public services including the risk of working with heavier workloads without better compensation even getting protests from the public and exposed through mass media. These changes and risks become apparent primarily in OPDs that focus on more effective public service changes. The score on the orientation dimension of people-oriented result, team, aggressiveness, steadiness, growth and pay attention to details is considered good. The level of cultural characteristics is also in the good category. The condition is considered sufficient but needs to be improved considering the cultural function of the orientation of the organization members in interpreting the problems and efforts in providing services to the community is quite complex.

Some other reasons for the importance of culture for OPD are (1) Interaction among members of the organization to realize accountability is regulated by certain values and norms that have meaning understood by members and be used as guidelines to act in order to achieve the goal of accountability, (2) the values and norms of the organization accountability are the foundation of values, confidence in assumptions and beliefs to solve problems, (3) decision-making processes must be guided by values and norms agreed upon and shared in the organization, (4) accountabilityoriented culture encourages the organization to influence the formation perception of the meaning of value in accountability.

For some OPDs that have a very strong shared value system as proposed by Robbins and Judge (2012), the changes in providing services to the community take place quickly and dynamically, unlike OPDs that lack common meaning in the face of change and the demands of society including problem-solving, innovation and the courage to take risks by pushing changes in the service which take place very slowly.

Observable artifacts from high-cultured OPDs in providing services to the public such as clean OPD buildings, conducive environments show a degree of convenience for service, technological support that demonstrates quality, and documentation systems that demonstrate the system and encourage employees to excel through an award-giving event. Regarding the espoused value, OPD that has a high culture in providing public services has an understanding of the purpose of the existence of public institutions/OPD, vision and mission achievement strategies, and the shared philosophy. These values as justification for the behavior and actions to realize the OPD remain oriented to optimal public services. At the basic underlying assumptions level, OPD members have the beliefs, perceptions, feelings and thoughts that become the source of action to solve new problems related to the effort to make OPD a credible government agency providing services. Public accountability is an indicator of the effective assessment of public service governance systems. To realize good governance a system that can support its implementation is required. The system is known as Performance Accountability of Government Institution. Government Institution 
Accountability System (SAKIP) is one form of responsibility of government organizers in performing their main duty and function. SAKIP is the implementation of performance management in the public sector that is consistent with the implementation of bureaucracy reform, which is oriented towards achievement of outcomes and efforts to obtain better results. In average, all the dimensions studied (orises, laws, policies, programs) are considered to be in less good category.

OPDs with good accountability are indicated by compliance with laws and regulations in the implementation of their functions including budget. In conducting every task and function, OPD in West Java province with high accountability have sufficient accounting information system, effective management information system, and standard administration procedure. Such support will affect how the work processes show accountability. Regarding the accountability of the local government, Yilmaz et al., (2008) propose a framework for accountability building, including citizen engagement with the government to complement the mechanism of public accountability. The dynamics of development demand accountability for the performance of local government institutions.

In accordance with the purpose of research, namely to examine the influence of internal control systems, leadership, organizational culture of OPD accountability, the analysis will use Structural Equation Modeling (SEM) approach that is measurement model and structural model.

The weight factor variable manifest of internal control system is valid. Average factor weight $>$ from 0.70. dimension $X_{1 \mathrm{D} .2}$ The Risk Assessment is the strongest in reflecting the latent variables of the internal control system. On the other hand, X1D.5 dimension (Monitoring) is the weakest in reflecting the latent variables of the internal control system with value of 0.730 . Average variance extracted value of three dimensions is 0.715 meaning that on average 71.5 percent of the information contained in each dimension can be reflected through the latent variables of the OPD internal control system in West Java. Then the value of the composite reliability of the latent variable internal control (0.962) is greater than the recommended value of 0.70 . It shows that the five dimensions have consistency level in measuring latent variable internal control system.

The weight factor of the three Leadership manifest variables is valid. The value of factor weights for each of the manifest variables can significantly reflect Leadership in OPD. The latent variable of Leadership (K), the dimension of $\mathrm{X}_{2 \mathrm{D} .1}$ (The determinant of organizational direction) is strongest in reflecting latent variables Leadership. On the other hand, $\mathrm{X}_{4 \mathrm{D} .1}$ dimension (Coach) is the weakest in reflecting latent variables Leadership. The value of Average Variance Extracted is 0.851, meaning that on average $85.1 \%$ of the information contained in each dimension can be reflected through the latent variable of Leadership. Then the value of composite reliability latent variable Leadership of 0.985 is greater than recommended value which is 0.70 . It indicates that the four dimensions have consistency to measure latent variable Leadership.

The weight factor of the seven manifest variables of organizational culture is valid. The value of factor weight for the manifest variable is significantly able to reflect the organizational culture.

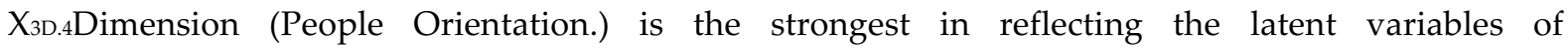

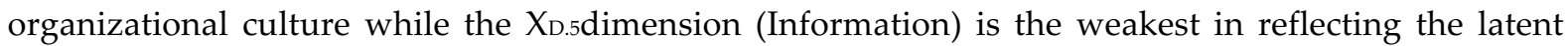
variables of organizational culture. The value of average Variance Extracted of the five dimensions is 0.7951, meaning that on average 79.51 percent of the information contained in each dimension can be reflected through the latent variable of organizational culture. Then the value of composite reliability latent variable of organizational culture is 0.976 , which is bigger than the recommended 0.70 . It shows that the five dimensions have a degree of steadiness in measuring the latent variable of organizational culture. The weighted value of the manifest variable factor is significantly capable of describing accountability. $Y_{\mathrm{D} .2}$ (process accountability) dimension is the strongest in reflecting latent variables of public accountability while the dimension of $Y_{\text {D..4 }}$ (reliability) is the weakest in reflecting latent variables of public accountability. The average variance extracted value is 0.757 meaning that on average, 86.9 percent of the information contained in each dimension can illustrate public accountability. Then, the value of composite reliability latent variable Public Accountability of 0.965 is greater than the recommended 0.70. It shows that the five dimensions have consistency in measuring latent variable of public accountability. 
The result of influence measurement in the absence of SPI found that the model is getting better. The results of the test are as follows:

Table 1 Goodness of fit model of the influence of leadership, organizational culture on public

\begin{tabular}{|c|c|c|c|c|c|}
\hline & \multicolumn{5}{|c|}{ accountability } \\
\hline Goodness & $\begin{array}{l}\text { Cut off } \\
\text { value }\end{array}$ & $\begin{array}{c}\text { Test Result with } \\
\text { SPI as an } \\
\text { Independent } \\
\text { Variable }\end{array}$ & $\begin{array}{c}\text { Test } \\
\text { Results } \\
\text { without } \\
\text { SPI }\end{array}$ & Analysis & $\begin{array}{c}\text { Conclusion of } \\
\text { Model } \\
\text { Comparison }\end{array}$ \\
\hline $\begin{array}{l}\text { Significance } \\
\text { Probability }\end{array}$ & $\geq 0.05$ & 0.00 & 0.00 & $\begin{array}{l}\text { It is } \\
\text { suggested to } \\
\text { review other } \\
\text { Fit Indices }\end{array}$ & \\
\hline RMSEA & $\leq 0.08$ & 0.071 & 0.08 & Moderate & Lower \\
\hline GFI & $\geq 0.90$ & 0.580 & 0.630 & Moderate & Better \\
\hline AGFI & $\geq 0.90$ & 0.555 & 0.6 & Moderate & Better \\
\hline CMIN/DF & $\leq 2$ or $\leq 3$ & 2.203 & 2.590 & Fit & Better \\
\hline TLI & $\geq 0.95$ & 0.827 & 0.839 & Moderate & Better \\
\hline CFI & $\geq 0.95$ & 0.832 & 0.846 & Moderate & Better \\
\hline PNFI & $>0.6$ & 0.709 & 0.739 & Fit & Better \\
\hline IFI & $>0.90$ & 0.833 & 0.847 & Moderate & Better \\
\hline
\end{tabular}

Source: Test Result of Model by Using SPSS.22

Based on fit model testing, it is known that without SPI, the model to solve the problem of OPD accountability becomes more fit. The model's fit indicator is better than the SPI as an independent variable. This proves that in the model is better without SPI. In accordance with the policy on accountable governance, the SPI is an integral part of local governance. Test results are presented in Figure 1.

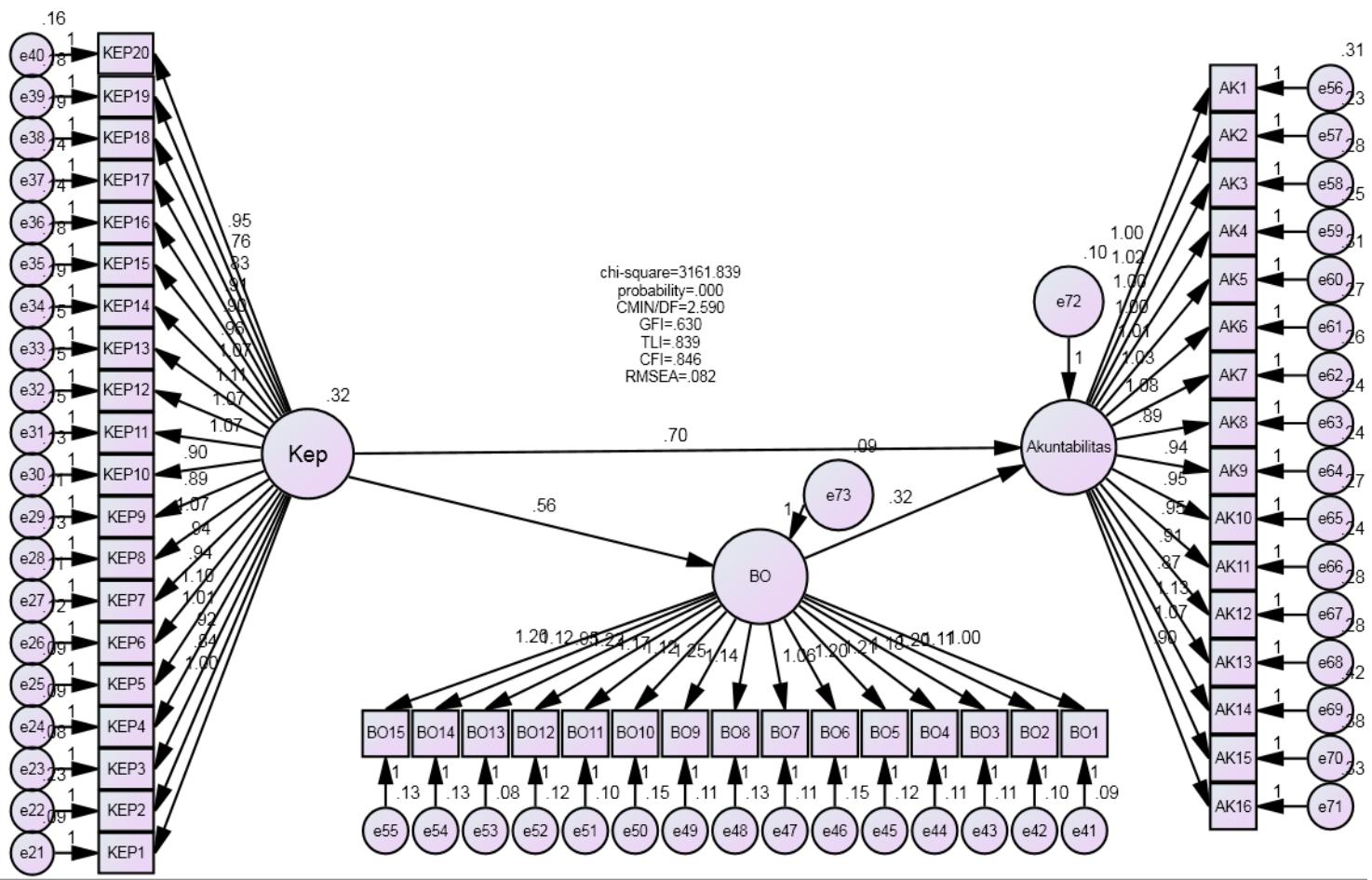

Figure 1 Results of model fit Test 
Based on the test results it is known that either directly or indirectly leadership can influence accountability. The direct influence of leadership is 70 percent while culture is 32 percent. It shows that the function of leadership is very strategic for the institution. Therefore, it is better to optimize the function of leader to solve accountability problem in OPD. The total influence is presented in Figure 2 .

Table 2 The Influence of Leadership, Organizational Culture on Public Accountability

\begin{tabular}{lrrr}
\hline & Lead. & OC & Accountability \\
OC & 0.563 & 0.000 & 0.000 \\
Accountability & 0.877 & 0.321 & 0.000 \\
\hline
\end{tabular}

Based on the table, the influence of leadership on accountability is 0.877 while the influence of culture is 0.56 . Culture is influenced by the leadership. Therefore, problem-solving in accountability is a matter of leadership. This is based on the results of research which shows the significant influence of leaders is even higher when the SPI is the absolute requirement of OPD management. It is in line with the results of a research by Steinbauier et al. (2011) which find that leadership affects accountability. Leadership affects employees' moral judgment in working to realize accountability. Ehrich et al. (2015) suggest that authentic leadership indicated by responsibility, openness, and problem-solving ability can serve as a variable for predicting accountability. The influence is in the high category. It is also reinforced by Pearson and Suterland (2017) which reveal the importance of leadership and value systems to create accountability. The 'Accountability System' model developed illustrates the interdependence between factors and the conceptualization of a process that can be followed by human resource professionals to develop institutional accountability as a shared value.

This result is in line with the system function in the organization as stated by Hernandez and Palacios (2014) that the internal control system is the moderation of organizational culture. In contrast, Pfister (2009) discusses the cultural function of the internal control system. Implementation of internal control system will strengthen the functions of leadership and existing values.

Leaders have strong legitimacy to optimize efforts to achieve accountability. The control system serves as the legitimacy of power for the leadership given the leadership in some OPD lose the legitimacy of integrity and morale. SPI becomes a system that serves to restore confidence in the leadership as the basis. It is difficult to establish strict criteria of leaders' election in OPD. Competence and individual characteristics cannot be used as the main basis of leadership choice by policy makers. The existence of an internal control system within the organization directs leadership behavior and leadership functions in influencing the overall system to build accountability.

In organizations that still have cultural weaknesses, SPI serves to strengthen organizational culture. Most OPDs have not been oriented to innovation or the courage to seek opportunities and pursue growth. The orientation towards people and results is still weak. The internal control system becomes a procedure or guideline that will direct employee behavior in accordance with accountability demands.

\section{Conclusions}

SPI can be used as a variable that strengthens the influence of leadership and culture on Accountability. The managerial implication is to optimize the function of the internal control system as a moderating variable of leadership and cultural influences on Accountability.

\section{References}

Abba, M., Mohammed, \& Kakanda, M. (2017). Moderating effect of internal control system on the relationship between government revenue and expenditure contribution/originality. Asian Economic and Financial Review, 7(74), 381-392.

André, R. (2010). Assessing the accountability of government-sponsored enterprises and quangos. Journal of Business Ethics, 97(2), 271-289. 
Aziz, M. A. A., Said, J., \& Alam, M. M. (2015). Assessment of the practices of internal control system in the public sectors of Malaysia. Asia-Pacific Management Accounting Journal, 10(1).

Babajanian, Babken V. (2008). Local governance in post-Soviet Armenia: Leadership, local development and accountability. Communist and Post-Communist Studies, 41, 375 -396.

Babatunde, S. A. (2013). Stakeholders perception on the effectiveness of internal control system on financial accountability in the Nigerian public sector. International Journal of Business and Management Invention, 2(1), 16-33.

Badara, M., \& Saidin, S. (2013). Impact of the effective internal control system on the internal audit effectiveness at local government level. Journal of Social and Development Sciences, 4(1), 16-23.

Bash, E. (2015). No Title No Title pigeon. PhD Proposal. Vol. 1.

Basri, H., \& Nabiha, A. K. S. (2014). Accountability of Local Government: The Case of Aceh Province, Indonesia. Asia Pacific Journal of Accounting and Finance, 3(1), 1-14.

Bellé, N. (2014). Leading to make a difference: A field experiment on the performance effects of transformational leadership, perceived social impact, and public service motivation. Journal of Public Administration Research and Theory, 24(1), 109-136.

Cowton, C. (2001). Editorial Introduction. Journal of Business Ethics, 34(3/4), Ethics: Leadership and Accountability: The 13th Annual EBEN Conference, 143

Crowe, J. (2011). New challenges for leadership and accountability in local public services in England. The International Journal of Leadership in Public Services, 7(3), 206-217.

Dzomira, S. (2014). Internal Controls and Fraud Schemes in Not-For-Profit Organisations: A Guide for Good Practice, 5(2), 118-126.

Dubnick, M. (2012). Accountability as Cultural Keyword

Ehrich, Lisa C., Harris, Jessica, Klenowski, Valentina, Smeed, Judy L., \& Spina, Nerida. (2015). The centrality of ethical leadership. Journal of Educational Administration, 53(2), 197-214.

Ellwood, S. M. (1993). Parish and Town Councils: Financial Accountability and Management. Local Government Studies, 19 (3)(December 2014), 368-386.

Erakovich, R., \& Kolthoff, E. (2016). Analysis of Ethical Leadership and Integrity Development in Local Government: The United States, The Netherlands, Montenegro, and Serbia. International Journal of Public Administration, 39(11), 872-882.

Fang, T. (2003). A Critique of Hofstede's Fifth National Culture Dimension. International Journal of Cross Cultural Management, 3(3), 347-368.

Frederick, H. R., Jr, W., \& Winston, B. E. (2016). The effect of the accountability variables of responsibility, openness, and answerability on authentic leadership. Journal of Research on Christian Education, 253(3), 1065-6219.

Ferry, L., \& Murphy, P. (2017). What about financial sustainability of local government-A critical review of accountability, transparency, and public assurance arrangements in England during austerity. International Journal of Public Administration, 1-11

Frey, B. S., Homberg, F., \& Osterloh, M. (2013). Organizational control systems and pay-forperformance in the public service. Organization Studies, 34(7), 949-972.

Gadenne, L. (2017). Tax me, but spend wisely? Sources of public finance and government accountability. American Econmic Journal: Applied Economic, 9(1), 274-314.

Gras, E., Hernandez, J., \& Palacios, M. (2014). An Explanation of Local Government Debt in Spain Based on Internal Control System. Lex Localis-Journal of Local Self-Government, 12(4), 775-792.

Hair J. V. Jr et al. (2013). Multivariate Data Analysis. USA: Pearson Education.

Hasu, M., \& Lehtonen, M. (2014). Leadership with care - Constructing responsibility as "shared caring" in a complex public service organisation. Scandinavian Journal of Public Administration, 18(4), 9-28.

Hepzibah, P., \& Kingdom, U. (2016). \$2.1 billion arms procurement fraud in Nigeria: Its impact on national security, peace and sustainable economic development in Jonathan's administration, 9(2), 225-248. 
Intruksi Presiden Republik Indonesia Nomor 7 tahun 1999 tentang Sistem Akuntabilitas Kinerja Instansi Pemerintah.

Jenkin, B. (2014). Accountability and leadership in twenty-first century Whitehall. The Political Quarterly, 85(1), 87-89.

Lee, M., Walker, A., \& Ling Chui, Y. (2012). Contrasting effects of instructional leadership practices on student learning in a high accountability context. Journal of Educational Administration, 50(5), 586-611.

Linnenluecke, M. K., \& Griffiths, A. (2010). Corporate sustainability and organizational culture. Journal of World Business, 45(4), 357-366.

Luminta, Ionescu (2008). The Appropriateness of an Internal Control System. Economics, Management, and Financial Markets, 3(1), 90-94. ISSN 1842-3191

MacDonald, T. (2016). Creating a culture of accountability. Training \& Development, 43(4), 15.

Mccall, J. J. (2012). Leadership and ethics: Corporate to whom, for accountability what and by what means? Journal of Business Ethics, 38(1/2), 133-139

Merchant, K. A., \& Otley, D. T. (2006). A Review of the Literature on Control and Accountability. Handbooks of Management Accounting Research, 2, 785-802.

Middaugh, M. F. (2007). Creating a culture of evidence: Academic accountability at the institutional level. New Directions for Higher Education, 140, 15-28

Morest, V. S. (2009). Accountability, accreditation, and continuous improvement: Building a culture of evidence. New Directions for Institutional Research, 17-27

Pearson, H., \& Sutherland, M. (2017). The complexity of the antecedents influencing accountability in organisations. European Business Review, 29(4), 419-439.

Pfister, J. (2009). Managing Organizational Culture for Effective Internal Control. From Practice to Theory. Berlin: Physica-Verlag Heidelberg

Resick, C., et al. (2011). What ethical leadership means to me: Asian, American, and European perspectives. Journal of Business Ethics, 101(3), 435-457.

Robbins, S and Judge. T.A (2013) Organizational Behavior. Global Edition. New York: Pearson Education Limited

Said, J., Alam, M. M., \& Aziz, M. A. B. A. (2015). Public accountability system: Empirical assessment of public sector of Malaysia. Asian Journal of Scientific Research, 8(2), 225-236

Sanusi, Z. M., Johari, R. J., Said, J., \& Iskandar, T. (2015). The Effects of Internal Control System, Financial Management and Accountability of NPOs: The Perspective of Mosques in Malaysia. Procedia Economics and Finance, 28(April), 156-162.

Steinbauer, R., Renn, R. W., Taylor, R. R., \& Njoroge, P. K. (2014). Ethical leadership and followers' moral judgment: the role of followers' perceived accountability and self-leadership. Journal of Business Ethics, 120(3), 381-392.

Stewart, J. G. and Kent, P. (2006). The relation between external audit fees, audit committee characteristics and internal audit. Bond Business School Publications.

Velayutham, S., \& Perera, M. H. B. (2004). The influence of emotions and culture on accountability and governance. Corporate Governance: The International Journal of Business in Society, 4(1), 52-64

Veljkovic.,N., Bogdanovi.,Dini, S., \& Stoimenov, L. (2014). Benchmarking open government: An open data perspective. Government Information Quarterly, 31(2), 278-290.

Yilmaz, S., Beris, Y., \& Serrano-Berthet, R. (2008). Local government discretion and accountability: A diagnostic framework for local governance, 113, 37. 